\title{
A mental health human resources strategy for Sri Lanka
}

\author{
H Minas
}

Sri Lanka is justly famed for, and proud of, the remarkable progress made in population health, well beyond what might be expected based on national income. These gains have no doubt been correctly attributed (1) to government leadership in matters such as public universal education and health services, the creation of community-level public health infrastructure, immunisation coverage, maternal and child nutrition, and training of and support for health workers. Despite the 2004 tsunami and the long-running armed conflict there has been a substantial improvement in the Human Development Index (HDI) since 1990 (2). Sri Lanka has the highest HDI in South Asia. Although disparities between regions and social groups continue to exist the poorest regions of the country are receiving increased attention, in line with the commitment to equity of the National Development Programme.

The national development programme (3) identified "absence of a realistic approved cadre, imbalance in the recruitment and production of different categories of staff, geographic inequity, imbalances in deployment and a disparity between expected job performance and training, including quality of training”, as key problems for human resource development. The human resources for health situation analysis commissioned by the Ministry of Health and published in 2009 (4) noted that the issues identified in national development programme "have persisted over several decades [and] have been documented in various policy documents though no concrete action has followed". Based on the situation analysis (4) the Human Resources for Health Strategic Plan (2009-2018) (5) highlighted a wide range of problems, which are summarised in the Table 1.

The HRH strategic plan was adopted in 2009 and it may be that many of the problems identified in the strategic plan have been resolved. However, many of the identified problems persist in the mental health system. In relation to mental health the HRH situation analysis noted that "Development of the country and the pressure and demand it exerts on the younger population may lead to increase of NCDs and mental health conditions in the future... The recently concluded conflict in the North and East has led to the need of rehabilitation of many young victims of war both mentally and physically in the future and the health sector has an important role to play in that scenario... There is an imperative need to look at the community level mental healthcare services in future reforms in HRH in Sri Lanka” (4). It was further suggested that "policy changes may be required in integrating public health and curative services at Primary Health Care level to include care of the elderly, Chronic NCD care and Mental Health services and in stren- gthening multi-sectoral involvement at divisional level to improve the mental health program (4), an issue that will acquire further momentum in the context of the sustainable development goals $(6,7)$.

The current Mental Health Policy for Sri Lanka (20052015) was developed in the immediate aftermath of the 2004 Indian Ocean tsunami (8). The Policy, and accompanying Action Plan, set out an ambitious program of mental health system reform and development in six areas: 1) management at national and provincial levels; 2) organisation of services; 3) human resource development; 4) research and ethics; 5) tackling stigma and promoting good mental health; and 6) mental health legislation.

Although the extent of implementation of the existing mental health policy has not been formally evaluated it is clear that considerable progress has been made in a number of areas, while progress in others has been slow. It is disappointing, for example, that 10 years after a first draft of mental health legislation was written a mental health act has still not been passed. Particularly notable among the achievements have been the remarkable transformation of the Colombo mental hospitals (including the establishment of the National Institute of Mental Health), the establishment of acute psychiatric units in many districts, a substantial increase in the number of psychiatrists, expansion of the Medical Officer of Mental Health program of training and deployment (9), establishment of the Diploma of Psychiatry training program, and training in mental health of primary health workers (10). Although the suicide rate is still high in Sri Lanka, and it is disturbing that maternal suicide is the leading cause of pregnancy-related deaths (11), the substantial reduction in the suicide rate (12) is an impressive example of effective intersectoral collaboration with major public health benefits. These and many other developments have built a solid platform for the next phase of development of the mental health system in Sri Lanka.

In 2014 the Mental Health Directorate of the Department of Health commenced the process of developing the national mental health policy for the next decade. Among the most important areas for action in the revised policy will be the development of a Human Resources for Mental Health (HRMH) strategy.

The 2006 Mental Health Action Plan included a detailed list of categories of mental health workers, the numbers of each that should be available in each of the main service elements and brief consideration of training requirements. The following core staff were identified 


\section{HRH Policy Development and Planning}

1.1. Weak HRH policy development process and planning processes. Limited capacity and inadequate evidence base for HRH policy development. Lack of direction in responding to population health needs. Unrealistic norms and projections.

\section{HRH Training and Production}

2.1. Recruitment. Recruitment of trainees ineffectively aligned with staffing requirements.

2.2. Quality of the training programs. Training and out-of-date curricula do not meet current service needs. Inadequate competency-based and problem-based learning. Inadequate training of teachers. Lack of rigorous evaluation of quality of training.

2.3. Degree programs. Production of health professionals is not based on service needs. Inadequate planning for absorbing allied health graduates into services.

2.4. In-service programs and continuous professional development (CPD). Absence of regular in-service programs for most categories of staff to update their competencies. CPD programs not well established.

2.5. Postgraduate program. Over-supply of some specialties, under-supply of others. Long waiting times for suitable overseas training. Non-return of postgraduates after foreign training.

2.6. Private sector. Numbers of trained nurses and other allied healthcare categories are below requirements of the private sector. Public sector health professionals working part-time in the private sector.

\section{HRH Management}

3.1. Weak human resources management capacity. No single unit or person responsible for human resources across the sector. Timely information on HRH not available to decision makers.

3.2. Inadequate human resource management (HRM) staff development. Low productivity of HRM staff.

3.3. Lack of coordination of HRM functions. Delays in personnel management (appointments, promotions, payments, etc.). Inadequate coordination between supply side and demand side units.

3.4. Unsatisfactory working conditions. Work environment for some is not conducive to productive work.

3.5. Workforce distribution, processes and procedures are not conducive to productive work. Inequities in workforce distribution.

3.6. Motivation among staff. De-motivation due to absence of a mechanism to recognise good work. Salary anomalies. Negative effects of dual practice.

3.7. Decentralisation. Decentralised system has led to difficulties in transferring staff in and out of provinces.

3.8. Trade union influence. Trade union actions.

3.9. Productivity and quality improvement and performance appraisal. Human resources not optimized to enhance health sector performance. Low workforce productivity.

3.10. Attitudes: Symptomatic responses to problems, mainly through political decision makers.

for each MoH area: 1 Medical Officer of Mental Health (MoMH), 2 Community Psychiatric Nurses (CPN), 1 Public Health Inspector (PHI) trained in mental health, 2 rehabilitation workers and at least 3 psychosocial workers. The Action Plan specified additional mental health staff for each district, and minimum staff for each acute psychiatric unit and for intermediate care units that included trained nurses, psychologists, social workers and occupational therapists. The plan envisaged a comprehensive training plan and identified the categories of mental health workers who would require training, and suggested the minimum duration of training, who would do the training and a very brief indication of the content of training.

Although progress has been made in a number of areas, many of the targets are far from being achieved, due primarily to the absence of a strategic plan for achieving the identified objectives. There is an urgent need to develop a comprehensive mental health human resources strategy (13). The strategy would need to be fully aligned with the Human Resources for Health Strategic Plan (2009-2018) (5), and should be guided by the WHO HRH Action Framework (14).

The current process of revision of the national mental health policy represents an opportunity to ensure that the effort to continually improve the mental health system does not neglect the most vital component of the mental health system, the mental health workforce. Without adequate numbers of skilled health workers, who are equitably distributed, adequately remunerated and encouraged and supported to continuously improve performance, other important elements of the national 
mental health policy cannot be effectively implemented and population mental health cannot be improved. Implementing and continuously monitoring and evaluating a comprehensive human resources for mental health strategy will require creative and sustained leadership at all levels and among all stakeholder groups, investment in education and training capacity and in the mental health service system, and strengthening of health management information systems.

Although all stakeholders must be engaged, psychiatrists should be particularly active in the creation and implementation of an HRMH strategy since, in addition to direct clinical work, they will be increasingly responsible for: a) leading multi-disciplinary mental health teams; b) training, supervising and mentoring other mental health workers; and c) ensuring the highest possible mental health system performance for the population they serve.

H Minas, Head, Global and Cultural Mental Health Unit, Centre for Mental Health, School of Population and Global Health, The University of Melbourne

E-mail: h.minas@unimelb.edu.au

\section{References}

1. Karunathilake IM. Health Changes in Sri Lanka: Benefits of Primary Health Care and Public Health. Asia Pac J Public Health 2012; 24(4): 663.

2. United Nations Development Programme. Human Development Report 2013: The rise of the South: Human progress in a diverse world. New York: United Nations Development Programme; 2013.
3. Ministry of Finance and Planning: Mahinda Chinthana. Vision for the Future. The development policy framework. Colombo: Government of Sri Lanka; 2006.

4. Ministry of Healthcare and Nutrition. Human Resources for Health Strategic Plan (2009-2018) - Situation analysis. Colombo: Ministry of Healthcare and Nutrition; 2009.

5. Ministry of Healthcare and Nutrition. Human Resources for Health Strategic Plan (2009-2018). Colombo: Ministry of Healthcare and Nutrition; 2009.

6. Minas H, Izutsu T, Tsutsumi A, Kakuma R, Lopez A. Asia-Pacific ready to act on mental health target in the SDGs. Lancet Psychiatry 2015; 2(3): 199-201.

7. Minas H, Tsutsumi A, Izutsu T, Goetzke K, Thornicroft G. Comprehensive SDG goal and targets for noncommunicable diseases and mental health. International journal of mental health systems 2015; 9: 12.

8. Mental Health Directorate. The Mental Health Policy of Sri Lanka: 2005-2015. Colombo: Ministry of Heathcare and Nutrition; 2005.

9. Jenkins R, Mendis J, Cooray S, Cooray M. Integration of mental health into primary care in Sri Lanka. Ment Health Fam Med 2012; 9(1): 15-24.

10. Budosan B. Mental health training of primary health care workers: case reports from Sri Lanka, Pakistan and Jordan. Intervention (15718883) 2011, 9: 125-36.

11. Fernando RN. Maternal suicide is the leading cause of pregnancy-related deaths in Sri Lanka. J Obstet Gynaecol Res 2013; 39(10): 1492-3.

12. Knipe DW, Metcalfe C, Fernando R, et al. Suicide in Sri Lanka 1975-2012: age, period and cohort analysis of police and hospital data. BMC Public Health 2014; 14: 839.

13. Kakuma R, Minas H, van Ginneken N, et al. Human resources for mental health care: current situation and strategies for action. Lancet 2011; 378(9803): 1654-63.

14. Dal Poz M, Gupta N, Quain E, Soucat A. Handbook on monitoring and evaluation of human resources for health with special applications for low- and middle-income countries. Geneva: World Health Organization; 2009. 